\title{
EVALUASI INTEGRASI NILAI GENDER PADA PENDIDIKAN MENENGAH (STUDI PADA SEKOLAH MENENGAH ATAS DI KABUPATEN SRAGEN)
}

\section{EVALUATION OF INTEGRATION OF GENDER IN SECONDARY EDUCATION (STUDY AT SENIOR HIGH SCHOOLS IN SRAGEN REGENCY)}

Tiyas Nur Haryani, Ismi Dwi Astuti Nurhaeni

Program Studi Ilmu Administrasi Publik Fakultas Ilmu Sosial dan Politik

Universitas Sebelas Maret

tiyasnurharyani@staff.uns.ac.id

\begin{abstract}
Abstrak
Pendidikan merupakan pelayanan primer dan dasar dalam aspek pembangunan sosial. Pembangunan sumber daya manusia bangsa dibangun lewat pendidikan baik formal dan non formal. Saat ini, usia anak-anak sampai dengan menginjak remaja banyak menghabiskan waktunya di sekolah. Lingkungan sekolah sebagai lingkungan pendidikan sekunder sudah memiliki input dominan dalam pembangunan akademik, ketrampilan dan karakter generasi bangsa. Sekolah menjadi bagian penting dalam mendidik anak baik dalam hal karakter sosial dan psikologis. Responsivitas gender penting untuk dibangun guna menghasilkan daya saing sumber daya manusia bangsa yang setara dan inklusif dalam pembangunan. Sekolah responsif gender penting untuk dikembangkan sejalan dengan kebijakan pengarusutamaan gender di Indonesia. Penelitian ini dilakukan di Kabupaten Sragen pada tahun 2017 studi kasus pada Sekolah Menengah Atas dan Sekolah Menengah Kejuruan di Kabupaten Sragen yang dipilih secara purposive. Data kualitatif dikumpulkan dengan pengamatan langsung, dokumentasi dan focus group discussion. Hasil penelitian menunjukkan bahwa penerapan sekolah responsif gender telah dilakukan oleh Sekolah Menengah Atas dan Sekolah Menengah Kejuruan di Kabupaten Sragen. Namun, penerapan sekolah responsif gender yang belum optimal karena masih rendahnya komitmen dan integrasi responsivitas gender oleh pejabat pembuat kebijakan sekolah. Hasil penelitian tetap memberikan saran agar perluasan sosialisasi standar dan nilai-nilai sekolah responsif gender terus dilaksanakan oleh stakeholders.
\end{abstract}

Kata Kunci: kesetaraan dan keadilan gender, pelayanan pendidikan, pengarusutamaan gender

Abstract 
Education is an important factor to building the country. Education starts from the family environment as primary environment. However, today more education takes place in a secondary environment. Schools play an important role in educating children both in terms of social and psychological characteristics. Gender responsiveness is important to build in order to produce the competitiveness of equal and inclusive human resources in development. Gender responsive schools are important to develop the country. This research was conducted in Sragen regency as representation from Indonesia with sample at several high school and vocational high schools selected purposively. Qualitative data were collected by observation, documentation and interviews. The results show that the implementation of gender responsive schools has been undertaken. However, some schools have not been able to implement gender responsive schools optimally due to the lack of commitment and integration of gender responsiveness by school policy-making officials. The results of research continue to provide suggestions for the extension of socialization of standards and values of gender responsive schools continue to be implemented by stakeholders.

\section{Keywords: gender equality, education service, gender mainstreaming}

\section{A. Pendahuluan}

Pendidikan memegang peran strategis dalam mengembangkan kualitas sumber daya manusia. Layanan dasar kepada warga negara mencakup layanan pendidikan dan kesehatan. Oleh karena itu, layanan pendidikan menjadi prioritas dalam setiap agenda pembangunan nasional dan di daerah. Saat ini, usia anakanak sampai dengan menginjak remaja banyak menghabiskan waktunya di sekolah. Lingkungan sekolah sebagai lingkungan pendidikan sekunder sudah memiliki input dominan dalam pembangunan akademik, ketrampilan dan karakter generasi bangsa.

Globalisasi, modernisasi dan kapitalisme global turut menjadi faktor perubahan sosial di masyarakat sehingga dominasi peran pendidikan yang lebih banyak diserahkan kepada lembaga pendidikan formal sekolah. Hal ini menjadi paradoks jika dibandingkan dengan amanat Undang-Undang Sistem Pendidikan Nasional Nomor 20 Tahun 2003 di mana Pasal 1 ayat 13, menyebutkan bahwa "pendidikan informal adalah jalur pendidikan keluarga dan lingkungan”. Penyediaan pendidikan berkualitas yang bersifat mandiri dari lingkungan keluarga di era modern ini menjadi persoalan dan tantangan yang harus dihadapi oleh seluruh lapisan masyarakat. Jailani (2014) dalam penelitiannya menyatakan bahwa saat ini pendidikan keluarga belum sepenuhnya dilaksanakan oleh para orang tua yang memiliki anakanak di rumah. Hal ini tentu saja 
turut menyumbang permasalahan dalam agenda pembangunan sumber daya manusia dalam rangka memperkuat pembangunan nasional.

Melihat latar belakang tersebut, pengembangan lembaga pendidikan sekolah untuk terus mengikuti perkembangan dan perubahan sosial menjadi kebutuhan bagi para stakehokders, baik pelaksana penyelenggara pelayanan publik bidang pendidikan maupun masyarakat selaku pengguna dan kelompok penerima manfaat. Salah satu aspek sosial yang saat ini perlu menjadi perhatian adalah pendidikan responsif gender. Indonesia mengalami darurat kekerasan seksual dengan jumlah kasus pada tahun 2011 sebesar 52\% kasus kekerasan seksual dari total 2.426 kasus, tahun 2012 sebesar 58\% kasus kekerasan seksual dari total 2.637 kasus, tahun 2013 menjadi 62\% kasus kekerasan seksual dari 3.339 kasus, tahun 2014 $52 \%$ kasus kekerasan srksual dari 3.762 kasus, tahun 2015, tercatat $59 \%$ kasus kekerasan seksual dari 2.898 kasus, pada 2016 tercatat 120 kasus kekerasan seksual terhadap anak dan pada tahun 2017 tercatat sebanyak 116 kasus kekeraasan seksual terhadap anak (Tuliah, 2018). Kekerasan seksual merupakan manifestasi ketidakadilan gender yang dapat berkaitan faktor subordinasi gender. Oleh karena itu integrasi nilai gender dalam bidang pendidikan penting untuk diimplementasikan.

Reformasi kebijakan yang mengintegrasikan gender telah masuk dalam agenda setting aktor kebijakan dan pelaksana kebijakan bidang pendidikan. Namun, kebijakan pengarusutamaan gender di bidang pendidikan belum mudah diimplementasi dan dioptimalkan oleh para pelaksana kebijakan (Nurhaeni, 2009). Pembangunan berkesataraan gender telah diintegrasikan dalam setiap agenda pembangunan di Indonesia lewat kebijakan pengarusutamaan gender. Akan tetapi paradigma pembangunan pemberdayaan perempuan dari Women in Develpment ke pengaruutamaan gender di Indonesia belum cukup mampu menjadi arus utama dalam pembangunan nasional (Nurhaeni, 2009). Sejak diterbitkannya Inpres Nomor 9 Tahun $2000 \quad$ tentang Pengarusutamaan Gender dalam Pembangunan Nasional pemerintah telah meningkatkan kesadaran dan kepekaan gender dalam berbagai program kebijakan (Matoka dan Hasan, 2016).

Padahal saat ini perkembangan di masyarakat membutuhkan pembangunan karakter yang adil dan setara gender pada anak-anak didik untuk membantu mereka mencapai potensinya secara optimal (Sterling \& Anne, 2014; Lahelma, 2014). 
Selain pada kasus kekerasan seksual, partisipasi dan keterbukaan akses pendidikan untuk anak laki-laki dan perempuan yang adil dan setara bagi anak laki-laki dan perempuan dibutuhkan untuk mencapai pemerataan pembangunan. Apabila kesetaraan dan keadilan gender dapat terintegrasikan seiring dengan pembangunan nasional maka pendidikan adil gender akan berkontribusi terhadap status sosial ekonomi negara. Isu gender pada dasarnya bersifat cross cutting issue. Hal ini memberikan implikasi pentingnya integrasi gender dalam setiap bidang dan ditangani secara kolaborasi antar bidang, tak terkecuali dalam bidang pendidikan sebagai prioritas pembangunan.

Penelitian ini fokus mengkaji responsivitas gender di lembaga pendidikan sekolah. Pendidikan sadar gender dalam pendidikan formal secara langsung dan secara tidak langsuang dalam bentuk interaksi antar individu menjadi kebutuhan untuk disosialisasikan. Lembaga sekolah menjadi wadah dalam mensosialisasikan berbagai budaya dan kebiasaan bagi anakanak didik. Menurut penelitian Hadi (2015) paradigma pengembangan kurikulum pendidikan karakter inklusi gender tidak bisa dilepaskan dari analisis gender. Penelitian ini melihat dari sisi implementasi sekolah yang responsif gender. Penelitian dilakukan dengan mengkaji pada variabel-variabel implimentasi dengan memilih teori Mazmanian dan Sabatier (1983). Dipilihnya teori ini karena mencakup variabel-variabel implementasi kebijakan yang cukup kompleks dibandingkan teori implementasi kebijakan yang lain seperti teori Grindle (1980) yang lebih cocok untuk persoalan implementasi kebijakan dengan menggunakan pendekatan proses politik serta teori Van Meter\& Carl E. Van Horn (1975) yang lebih cocok untuk persoalan implementasi kebijakan dengan focus pada komunikasi antara orgaanisasi dan aktivitas pemaksa, karakteristik lembaga pelaksana kebijakan, kondisi sosial, ekonomi dan politik serta ketersediaan sumberdaya dan disposisi implementor kebijakan. Dengan menggunakan teori Mazmanian dan Sabatier (1983) maka dapat diketahui apakah persoalannya terletak pada variabel kesulitan-kesulitan teknis (Tractability of the Problem), kemampuan di dalam menstrukturkan implementasi kebijakan (Ability of Statute to Structure Implementation), Variabledi luar non statute yang berpengaruh terhadap implementasi kebijakan (Nonstatory Variables Affecting Implementation) ataukah pada proses implementasinya (Stages in the Implementation Process).

\section{B. Metode Penelitian}


Penelitian ini memfokuskan tentang implementasi sekolah responsif gender studi kasus implementasi pendidikan di Kabupaten Sragen. Penelitian ini dilaksanakan di Kabupaten Sragen, Provinsi Jawa Tengah. Dipilihnya Kabupaten Sragen karena berdasarkan Human Development Index (HDI), Indeks Pembangunan Gender (Genderrelated Development Index) dan Indeks Pemberdayaan Gender (Gender Empowerment Measure), Kabupaten Sragen merupakan salah satu Kabupaten/kota di Jawa Tengah yang masuk dalam kategori terendah dibandingkan kabupaten/kota lain di Jawa Tengah. HDI Kabupaten Sragen pada tahun 2012 sebesar 71,85 dan berada di peringkat ke-25, GDI sebesar 67,23 dan berada diperingkat ke 15 serta GEM sebesar 57,58 dan berada di peringkat ke-27. Sekolah dipilih scara purposive dari 31 SMA di Kabupaten Sragen, dipilih dengan pertimbangan: (1) Sekolah sudah pernah mengikuti Capacity Building Pengarusutamaan gender bidang pendidikan; (2) Termasuk dalam salah satu kategori sebagai SMA Negeri dan SMK Negeri; (3) Termasuk dalam kategori SMK dominan siswa laki-laki atau dominan siswi perempuan. Data dikumpulkan dari dokumen terkait, pengamatan di lapangan dan wawancara kepada para pejabat SMA Negeri dan SMK Negeri terpilih sampel penelitian ini.
Analisis data dilakukan dengan triangulasi sumber.

\section{Hasil dan Pembahasan}

Sekolah Responsif Gender mengandung unsur seperti unsur akademik, unsur sosial, unsur lingkungan fisik, dan unsur masyarakat, yang harus memperhatikan perbedaan kebutuhan laki-laki dan perempuan. Perbedaan kebutuhan antara laki-laki dan perempuan harus direspon dengan baik dan maksimal agar mampu mendorong kemajuan prestasi dari peserta didik laki-laki dan perempuan. Sekolah responsif gender perlu mengetahui bahwa laki-laki dan perempuan itu berbeda secara biologis dan kontruksi sosial. Perbedaan kondisi ini memiliki konsekuensi dalam pemenuhan fasilitas yang berbeda untuk laki-laki dan perempuan.

Penelitian sekolah responsif gender studi kasus di Kabupaten Sragen berhasil memotret pelaksanaan tentang Sekolah Responsif Gender. Pada pelaksanaannya sampai saat ini gender belum diimplementasikan maksimal dalam sekolah, khususnya dalam penyediaan sarana prasarana fasilitas pendukung lingkungan sekolah. Selain itu, saat ini masih ada masalah dalam pelabelan pada peserta didik laki-laki dan perempuan. Kasus yang ditemukan dalam penelitian ini dalam aspek pelabelan adalah kasus kehamilan di 
luar nikah pada siswi. Stereotip gender lebih banyak memberikan dampak negatif bagi siswa perempuan dibandingkan siswa lakilaki dalam kasus kekerasan seksual dalam pacaran. Peserta didik perempuan yang ketahuan hamil akan mendapat sanksi berupa dikeluarkan atau diminta untuk mengundurkan diri. Sedangkan lakilaki tidak diminta melakukan hal yang sama sekalipun keduanya berada dalam relasi yang memicu terjadi kekerasan seksual dalam pacaran. Hasil penelitian menunjukkan masih adanya subordinasi atau meninggikan salah satu jenis kelamin yang berdampak pada muculnya kekerasan gender. Kekerasan sering kali bersifat psikologis, dan hal tersebut berpengaruh terhadap peserta didik. Gender menjadi masalah apabila salah satu jenis kelamin dirugikan.

Integrasi gender penting dilakukan di dunia pendidikan karena kita sering menemukan stereotip bahwa prestasi peserta didik perempuan lebih baik dari peserta didik laki-laki. Namun, dalam hal mendapatkan pekerjaan setelah lulus, lulusan perempuan belum berhasil mendapatkan kesempatan yang sama dengan lulusan laki-laki saat melamar pekerjaan. Kecenderungan yang lebih mudah mendapat pekerjaan adalah laki-laki sekalipun perempuan cenderung memiliki prestasi yang cemerlang di sekolah.
Pada penelitian ini juga menemukan best ptactice menyelenggaraan sekolah yang responsif gender. Ada salah saru sekolah dalam sampel penelitian yang menanamkan aspek budaya kesetaraan gender di lingkungan sekolah dalam bentuk pembiasan-pembiasaan mengenai bagaimana mengimplementasikan gender dalam kehidupan sehari-hari di sekolah secara sederhana. Salah satu sekolah dalam sampel terpilih mulai membangun sistem dan fasilitas mushola untuk laki-laki dan perempuan. Hal tersebut sudah menjadi wujud dari implementasi sekolah responsif gender, pemisahan sarana dan prasarana tersebut dapat ditujukan untuk mendorong kesetaraan gender.

Akan tetapi, keragaman sosial masyarakat masih menjadi faktor penghambat keberhasilan pengembangan responsivitas gender dari lembaga pendidikan. Masyarakat yang masih kental dengan budaya patriaki melanggengkan ketimpangan relasi gender. Penempatan kaum perempuan dalam ranah domestik secara dikotonomis menjadi penghalang berkembangannya perempuan di dunia publik, khususnya di lingkungan masyarakat pedesaan. Oleh karena itu para informan dari kelompok guru yang mengakui bahwa perlu ada langkah penting sebagai guru dalam mengatasi nilai-nilai yang sudah 
berkembang di masyarakat yang menghambat kesetaraan gender. Guru dapat membangun peran selaku motivator masyarakat sekitar dan dapat ikut serta membangun komunikasi dengan orang tua peserta didik untuk menyampaikan mengenai pandangan dan pengertian tentang kesetaraan gender.

Hambatan lainnya dalam implementasi sekolah responsif gender adalah komitmen kebijakan dari pihak pembuat kebijakan daerah maupun lingkup sekolah. Salah satu informan menjelaskan bahwa bagi guru-guru di sekolahnya dalam mengimplementasikan sekolah responsif gender mengalami kendala terkait komitmen kebijakan yang masih lemah dari para pembuat keputusan. Selain itu, hal tersebut didukung dengan lemahnya kapasitas pendidikn yang telah terinternalisasi wawasan dan pengetahuan mengenai pengarusutamaan gender, sehingga sulit dalam transfer knowledge internalisasi gender pada peserta didiknya.

Faktor penghambat implementasi Sekolah Responsif Gender di Kabupaten Sragen dilihat dari teori Mazmanian dan Sabatier antara lain sebagai berikut:

1. Hambatan Variabel Tracability of the Problem

1.1 Belum ada komitmen dari pejabat pengambil keputusan
1.2 Belum ada lembaga konsultasi gender bagi para pejabat pengambil keputusan

1.3 Masih sulit dalam mengoperasionalkan

kebijakan pengarusutamaan gender dalam aktivitas sekolah

1.4 Belum ada wadah lembaga atau forum untuk konsultasi implementasi sekolah responsif gender

1.5 Masih ada penyelenggaraan pendidikan dan lembaga sekolah yang masih buta gender

1.6 Belum adanya panduan yang baku ataupun petunjuk pelaksanaan sekolah responsif gender

2. Hambatan dari Variabel The Ability of the Statue to Structure Implementation

2.1 Kesulitan dalam penyusunan visi, misi, dan strategi yang responsif gender

2.2 Belum ada peraturan khusus terkait sekolah responsif gender

2.3 Masih adanya masalah pemberian seragam sekolah yang rentan menimbulkan bullying pada salah satu jenis kelamin

2.4 Belum ada akses formal bagi pihak luar dalam melakukan kemitraan dan kolabirasi dalam implementasi sekolah responsif gender 
3. Hambatan dari Variabel Nostatutory Variables Affecting Implementation

3.1 Masih ada budaya patriarki

3.2 Masih ada (lebih 50\%) masyarakat menolak perempuan menjadi pemimpin

3.3 Orang tua cenderung memilih program studi berbasis teknologi untuk anak laki-laki

3.4 Orang tua cenderung memilih program studi berbasis tata boga/ administrasi bagi anak perempuan

3.5 Kondisi ekonomi masyarakat berpengaruh terhadap kesempatan perempuan melanjutkan pendidikan

3.6 Masyarakat kurang mampu cenderung memilih anak perempuannya untuk keluar dari sekolah

4. Hambatan dari Variabel Stage in the Implementation Process

4.1 Pengawasan integrasi gender dalam indikator sekolah masih lemah

\section{Penutup}

Hasil penelitian ini dapat memberikan kesimpulan antara lain:

1. Yang paling krusial dari indikator pertama adalah masih belum ada gambaran nyata mengenai bagaimana gender diimplementasikan.
2. Dalam bidang pendidikan dan implementasi responsivitas gender di sekolah membutuhkan forum Gender Vocal Point

3. Pelaksana kebijakan pengarusutamaan gender membutuhkan aksesibilitas informasi dan peningkatan kapasitas untuk penguatan sumber daya manusia pelaksana kebijakan arus utama gender di bidang pendidikan, khususnya bagi tenaga pendidik dan tenaga kependidikan.

4. Dalam hasil penelitian ini didapatkan temuan bahwa masih ada diskriminasi antara siswa lakilaki dan siswa perempuan. Hal ini masih disebabkan oleh reproduksi biologis pada kaum perempuan yang berbeda dengan kaum lakilaki. Kesempatan bekerja bagi siswa laki-laki dan siswa perempuan dari Sekolah Mengah Kejuruan menjadi berbeda, dengan anggapan bahwa tenaga kerja laki-laki karena tidak ada hambatan reproduksi.

5. Pada sisi marginalisasi terhadap perempuan peluang kerja bagi siswa perempuan menjadi besar sebab adanya pandangan upah pekerja murah pada tenaga kerja perempuan.

6. Dalam lingkungan di sekolah, siswa perempuan masih sangat rentan terhadap kekerasan psikis dan kekerasan seksual dari lawan jenisnya di lingkungan sekolah. 
Daftar Pustaka

Grindle, Merilee S (ed). 1980. Politics and Policy Implementation in The Third World. New Jersey: Princenton University Press.

Hadi, Sofiyan. 2015. Menggagas Pendidikan Karakter Responsif Gender. PALASTREN, Vol. 8, No. 2, Desember 2015

Lahelma, Elina. 2014. Troubling Discourses

On Gender And Education.

Educational Research Jun 2014, Vol. 56 Issue 2, P171183.

Matoka, Ulfa dan Abdul Hasan. 2016. Analisis Kesetaraan Gender dalam Penguatan Kelembagaan Universitas Halu Oleo. Jurnal Ekonomi (JE) Vol.1(1), April 2016.

Mazmanian, Daniel A dan Sabatier, Paul A. 1983. Implementation and Public Policy. USA: Scott, Foresman and Company.

Nurhaeni, Ismi Dwi Astuti. 2009. Kebijakan Publik Pro Gender. Surakarta: UNS Press.

Sterling, Fausto \& Anne. 2014. Shoot Down Gender Bias Before It Shoots You. Tes: Times Educational Supplement. 3/28/2014, Issue 5088.

Tuliah, Sabda. 2018. Kajian Motif Pelaku Kekerasan Seksual Terhadap Anak melalui Modus Operandi di Lingkungan
Keluarga. eJournal SosiatriSosiologi, Volume 6, Nomor 2, 2018: 1-17.

Undang-Undang Sistem Pendidikan Nasional Nomor 20 Tahun 2003

Van Meter, Donald S. \& Carl E. Van Horn. 1975. "The Policy Implementation Process : A Conceptual Framework" in Administration \& Society, Vol.6 No.4, February 1975. 
Spirit Publik Volume 14, Nomor 1, April 2019

Halaman 94-102

P-ISSN. 1907-0489 E-ISSN 2580-3875 